\title{
Application of Analyte Harvesting Nanoparticle Technology to the Measurement of Urinary HGH in Healthy Individuals
}

Alessandra Luchini ${ }^{*}$, Davide Tamburro ${ }^{1}$, Ruben Magni ${ }^{1}$, Claudia Fredolini ${ }^{1}$, Virginia Espina ${ }^{1}$, Jaume Bosch ${ }^{2}$, Enrico Garaci ${ }^{3}$, Emanuel F Petricoin III ${ }^{1}$ and Lance A Liotta ${ }^{1}$

${ }^{1}$ Center for Applied Proteomics and Molecular Medicine, George Mason University, Manassas, VA, USA

${ }^{2}$ Pharmacology Research Unit, Municipal Institute of Medical Research (IMIM), Department of Experimental and Health Sciences, Pompeu Fabra University (UPF), C/ Doctor Aiguader 80, 08003-Barcelona, Spain

${ }^{3}$ /stituto Superiore di Sanità, Rome Italy

\begin{abstract}
Urine represents a valuable biofluid for noninvasive measurement of Human Growth Hormone (HGH) secretion. Unfortunately, currently available commercial HGH immunoassays do not achieve the sensitivity needed for urinary $\mathrm{HGH}$ measurement in the low picogram per milliliter range, the expected normal concentration range of $\mathrm{HGH}$ in urine.
\end{abstract}

A nanotechnology based sample preprocessing step was used to extract and concentrate $\mathrm{HGH}$ in urine so that urinary HGH could be measured with a clinical grade standard immunoassay designed for serum (Immulite 1000, Siemens). We applied the nanoparticle enhanced immunoassay to evaluate the baseline value of urinary HGH in a population of healthy young adults (age 18-30, $\mathrm{N}=33$, median $21, \mathrm{M}: \mathrm{F}=39 \%: 61 \%$, with no reported medical therapies).

Nanoparticle sample preprocessing effectively improved the lower limit of detection of the Immulite HGH assay by more than 50 fold, shifting the linear range of the assay to encompass the expected value of urinary HGH. The full process between run and within run $\mathrm{CV} \%$ was 7.9 and $9.0 \%$, respectively. On 33 healthy volunteers, the $95 \%$ reference values for $\mathrm{hGH}$ in spot urine normalized to specific gravity were $0.64-16.85 \mathrm{pg} / \mathrm{mL}(0.05-5.82 \mathrm{ng} / \mathrm{g}$ creatinine).

Nanoparticle preprocessing constitutes a reliable means of measuring urinary HGH with a clinical grade immunoassay, now establishing a normal baseline value for $\mathrm{HGH}$ in urine. Nanoparticles can be used to study the kinetics of $\mathrm{HGH}$ excretion in urine, and the factors that influence urinary $\mathrm{HGH}$ secretion and $\mathrm{HGH}$ isoform proportions.

Keywords: Nanoparticles; Human growth hormone; Immunoassay; Reference values; Urine

\section{Introduction}

The importance of measuring Human Growth Hormone (HGH) levels in the clinical chemistry laboratory is growing rapidly for several reasons. Firstly, therapeutic administration of hGH has expanded beyond the treatment of short stature to now encompass traumatic brain injury [1], Turner syndrome [2] and aging [3]. Secondly, the abuse of hGH supplementation for enhancement of sport performance is believed to be widely prevalent [4]. While hGH testing is usually done in serum, there is a growing need for the measurement of hGH in urine $[5,6]$. Urine represents a valuable biofluid for noninvasive measurement of HGH secretion [7]. Unfortunately, currently available commercial HGH immunoassays, not based on radioactive labels, do not achieve the sensitivity needed for urinary HGH measurement. The Lower Limit of Detection (LLD) of the Immulite HGH serum immunoassay, Immulite 1000 (Siemens) is $50 \mathrm{pg} / \mathrm{mL}$, a value similar to the LLD for the current commercial (non-radiometric) immunoassays for $\mathrm{HGH}$ or its isoforms in blood [8]. This LLD is 50 fold above the postulated concentration of urinary hGH in healthy individuals, estimated to be in the range of $1 \mathrm{pg} / \mathrm{mL}$, as reported using ultrafiltration concentration and radioimmunoassay measurements conducted in the 1990s [7,9].

Thus, despite the fact that clinical researchers and basic scientists in the field of hGH research urgently need a simple and reliable assay for hGH in urine [6], commercial immunoassays designed for serum cannot be used for urine hGH testing. To address this need, in the present study we have applied hydrogel harvesting nanoparticles as a preprocessing step for HGH measurement in urine. Nanoparticles are added to the urine samples to concentrate the analyte into a small volume, which can then be eluted and measured by a clinical grade standard immunoassay designed for serum (Figure 1). The nanoparticles can rapidly harvest, protect from degradation, and concentrate, low abundance analytes from biologic fluids while actively excluding high abundance proteins such as albumin [10-13].
Applied as a simple one-step biospecimen pre-processing addition, the nanoparticles can improve the lower limit of analyte detection while preserving the linearity and precision of the analytical platform. In this study, we applied analyte harvesting hydrogel nanoparticles $[10,11]$ to reduce the LLD of the Immulite clinical serum immunoassay for HGH. The Immulite Growth Hormone (HGH) (Recombinant 98/574) is a standard two site sandwich immunoassay which reports a lower of detection of $0.050 \mathrm{ng} / \mathrm{mL}$. The nanoparticle preprocessing as described herein, reduces the LLD by more than 50 fold, shifting the linear range of the assay to encompass the expected value of urinary HGH. Here we report the use of nanoparticle preprocessing to establish an initial reference range value for urinary human growth hormone (hGH) in healthy young adults (age 18-30, N=33, median $21, \mathrm{M}: \mathrm{F}=39 \%: 61 \%$, with no reported medical therapies), using the Immulite hGH serum immunoassay, Immulite 1000 (Siemens).

\section{Materials and Methods}

\section{Subjects}

We collected urine and blood from 33 healthy young adults (age

*Corresponding author: Alessandra Luchini, Center for Applied Proteomics and Molecular Medicine, George Mason University, 10900 University Blvd BRH rm 325, Manassas VA 20110, USA, Tel: 703993 8945; Fax: 703993 8606; E-mail: aluchini@gmu.edu

Received October 02, 2012; Accepted October 26, 2012; Published October 29, 2012

Citation: Luchini A, Tamburro D, Magni R, Fredolini C, Espina V, et al. (2012) Application of Analyte Harvesting Nanoparticle Technology to the Measurement of Urinary HGH in Healthy Individuals. J Sports Med Doping Stud 2:116. doi:10.4172/2161-0673.1000116

Copyright: ( 2012 Luchini A, et al. This is an open-access article distributed under the terms of the Creative Commons Attribution License, which permits unrestricted use, distribution, and reproduction in any medium, provided the original author and source are credited. 
18-30, median 21, M:F=39\%:61\%, with no reported medical therapies). Spot urine $(>30 \mathrm{~mL})$ collections were done in a standardized time period in the morning (10 to $11 \mathrm{AM}$ ). The study was approved by the George Mason University Human Subjects Review Board (protocol GMU \# 6081) and conformed to the code of ethics of the world medical association (Declaration of Helsinki), printed in the British Medical Journal (18 July 1964). All subjects gave written informed consent.

\section{Nanoparticle synthesis}

Poly N-isopropylacrylamide (NIPAm) co- Acrylic Acid (AAc) nanoparticles were produced by precipitation polymerization and covalently linked to the chemical reactive dyes via zero link amidation reaction [10].

In order to prepare poly (NIPAm-co-AAc) particles, 4.750 grams of NIPAm (Aldrich) and 0.400 grams of $\mathrm{N}, N^{\prime}$-methylenebisacrylamide (BIS, Aldrich) were dissolved in $500 \mathrm{ml}$ of Milli-Q water. The solution was filtered under vacuum and transferred to a three neck round bottom flask under medium stirring. $500 \mu \mathrm{l}$ (0.525 gr) of AAc (Sigma Aldrich) was added to the round-bottom flask and the solution was purged with nitrogen for 30 minutes. The temperature of the solution was increased to $70^{\circ} \mathrm{C}$ and held constant for 15 minutes. 0.276 grams of Potassium persulfate (KPS, Sigma Aldrich) were dissolved in $5 \mathrm{~mL}$ of water and added to the round bottom flask. The reaction was help at $70^{\circ} \mathrm{C}$ for six hours and let cool overnight. Unreacted monomer was washed by centrifugation $\left(19,000 \mathrm{rpm}, 50\right.$ minute, $\left.20^{\circ} \mathrm{C}\right)$ with MilliQ water. Particles were re-suspended in a final volume of $600 \mathrm{~mL}$.

In order to covalently link organic reactive dyes to poly (NIPAmco-AAc) particles, a preliminary activation of the carboxylic group present in the nanoparticles was performed. Briefly, $20 \mathrm{~mL}$ of particle suspension prepared as described before were re-suspended in $0.2 \mathrm{M}$ Monobasic Phosphate Sodium $\left(\mathrm{NaH}_{2} \mathrm{PO}_{4}\right) \mathrm{pH}$ 5. The particle suspension was transferred in a round flask and $1 \mathrm{~mL}$ of $1 \%$ SDS (w/v), $824 \mathrm{mg}$ of N-(3 Dimethylaminopropyl) N' ethyl carbodiimide hydrochloride (EDC; Fluka Analytical) and 612 of solid N-Hydroxysuccinimide (NHS; Sigma-Aldrich) were added. The reaction was held at room temperature and medium stirring rate for 15 minutes. Meanwhile, organic dye (Remazol Brilliant Blue R, Sigma $=0.151 \mathrm{~g}$, Acid Blue 22, Sigma $=0.178$ $\mathrm{g}$, Brilliant Blue R250, Fisher $=0.2 \mathrm{~g}$, Cibacron Blue F3GA, Polysciences $=0.2 \mathrm{~g}$, Rhoda mine 123, Sigma $=0.09 \mathrm{~g}$ ) was dissolved in $50 \mathrm{~mL}$ of $0.2 \mathrm{M}$ Dibasic Phosphate Sodium $\left(\mathrm{Na}_{2} \mathrm{HPO}_{4}\right) \mathrm{pH} 9$ and filtered through a $0.22 \mu \mathrm{m}$ cellulose acetate membrane (Corning). Due to inferior solubility in aqueous buffers, the dyes Disperse Orange 3, Sigma = $0.058 \mathrm{~g}$, Pararosaniline Base, Sigma $=0.073 \mathrm{~g}$ were dissolved in $25 \mathrm{ml}$ of ethanol, $5 \mathrm{ml}$ of $1 \% \mathrm{SDS}$ and $25 \mathrm{ml}$ of $0.2 \mathrm{M} \mathrm{Na}_{2} \mathrm{HPO}_{4} \mathrm{pH} 9$ and filtered through a $0.22 \mu \mathrm{m}$ cellulose acetate membrane (Corning). After 15 minutes of activation reaction, the particle suspension was centrifuged (16.1 rcf, 15 minutes, $25^{\circ} \mathrm{C}$ ), the supernatant was discarded and the particle pellet was re-suspended in the dye solution. The reaction was held at room temperature at medium stirring rate overnight. In order to eliminate the un-reacted dye, particles were washed ten times with water by centrifugation $\left(19,000 \mathrm{rpm}, 50\right.$ minutes, $\left.25^{\circ} \mathrm{C}\right)$. Supernatants were disposed and particles re-suspended in $20 \mathrm{~mL}$ of MilliQ water.

\section{Nanoparticle characterization}

Particles were characterized by atomic force microscopy (AFM) using an NSCRIPTOR ${ }^{\text {ma }}$ DPN $^{\star}$ System (NanoInk). Particles solution (1 $\mu \mathrm{g} / \mathrm{ml}$ ) was deposited on freshly cleaved mica under humid atmosphere for 15 minutes and dried under nitrogen before measurement. Images were acquired under AC mode using a silicon tip with a typical resonance frequency of $300 \mathrm{kHz}$ and a radius smaller than $10 \mathrm{~nm}$.

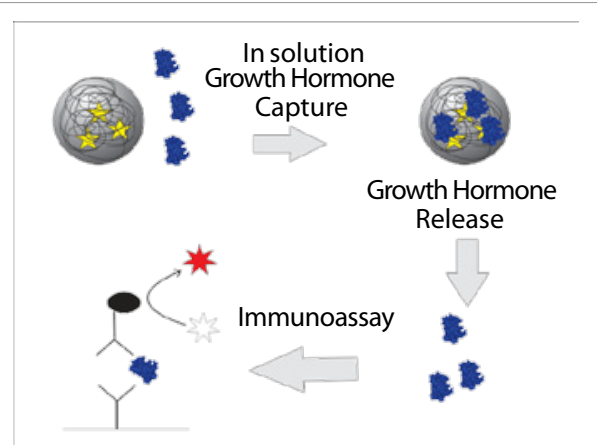

Figure 1: Capturing hydro gel nanoparticles pre-processing step. Well disperse and buoyant particles are introduced in the urine and all the solution phase Human Growth Hormone $(\mathrm{HGH})$ is sequestered. Particles are separated from the urine and captured $\mathrm{HGH}$ is eluted and analyzed with a sandwich immunoassay.

Incorporation of dye in the particles was assessed by weighing the dry particles before and after dye coupling.

\section{Urinalysis, specific gravity and creatinine measurement}

Dipstick urinalysis, specific gravity and creatinine measurement were performed on freshly collected urine before particle incubation. Urinalysis was performed with Siemens Multistix 10SG. Specific gravity was measured by means of a digital refractometer (Atago). Creatinine was measured by Creatinine Parameter Assay Kit (R\&D systems) according to the manufacturer instructions.

\section{Nanoparticle preprocessing of urine}

Aliquots of $30 \mathrm{~mL}$ of urine were centrifuged $(3,000 \mathrm{rpm}, 10$ minutes, $20^{\circ} \mathrm{C}$ ) in order to remove cell debris. Urine $\mathrm{pH}$ value was measured by and adjusted to 5 with $1 \mathrm{M} \mathrm{HCl}$ if necessary. Urine was incubated with $3 \mathrm{~mL}$ of poly (NIPAm/RBB) nanoparticles for 30 minutes. The nanoparticles were separated by centrifugation $(20,000 \mathrm{rpm}, 40$ minutes, $25^{\circ} \mathrm{C}$ ). Protein cargo was eluted with $70 \%$ acetonitrile $10 \%$ ammonium hydroxide and dried under nitrogen flow (Organomation).

\section{Immulite 1000 growth hormone immunoassay}

The concentration of HGH eluted from particles was measured using the Immulite 1000 Immulite Growth Hormone (HGH) (Recombinant 98/574) (Siemens Medical Solution Diagnostic). Particle eluates were dried under nitrogen flow, the dried proteins were dissolved in $0.3 \mathrm{~mL}$ of Immulite GH sample diluent and hGH was measured according to manufacturer instructions for serum hGH.

\section{Statistical analysis}

Reference values and confidence intervals were calculated with the bootstrap method [14] in R Statistical Software [15].

\section{Results}

\section{Nanoparticle bait screening}

A key element of the hydrogel nanoparticles is the incorporation of the bait $[9,10]$, which captures HGH with high affinity. We screened a series of nine chemical baits for HGH affinity within a urine matrix. The affinity ranges from $\mathrm{K}_{\mathrm{D}}=10^{-9}$ to $10^{-12} \mathrm{M}$. We selected the bait that had the highest affinity, which was Remazol Brilliant Blue R (RBB, Figure 1). This previously unpublished bait for HGH had an affinity ten times greater than Cibacron Blue F3GA [12,13] (Figure 2). 


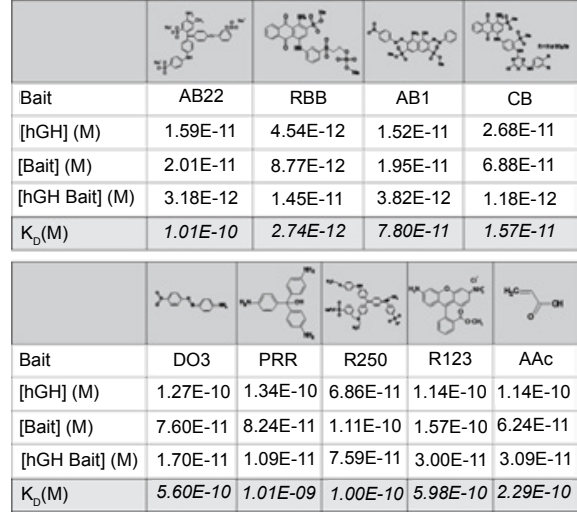

Figure 2: Dissociation constant $\left(\mathrm{K}_{\mathrm{D}}\right)$ values calculated for nine organic chemical baits assuming hGH-bait equimolar binding. $\mathrm{AB} 22=$ Acid blue 22 $\mathrm{RBB}=$ Remazol brilliant blue $\mathrm{R}, \mathrm{AB} 1=$ Acid black $1, \mathrm{CB}=$ Cibacron blue F3GA DO3 $=$ Disperse orange 3, PRR $=$ Pararosaniline base, R250 $=$ Brilliant blue R250, R123 = Rhoda mine 123, AAc = acrylic acid
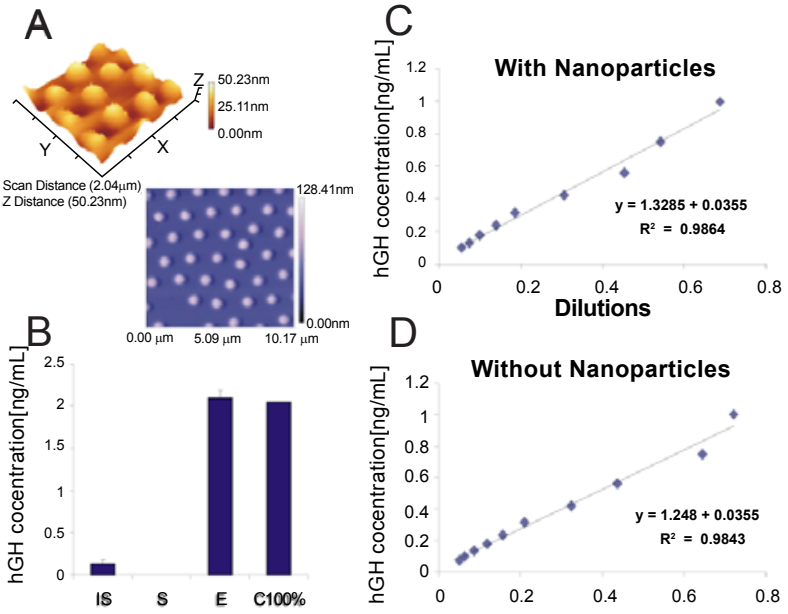

Figure 3. A) Atomic force microscope images demonstrate uniformity of the spherical poly (NIPAm/RBB) nanoparticles. B) Nanoparticle-Immulite GH assay has a within run $\mathrm{CV}=9 \%$ (over ten replicates) and virtually $100 \%$ yield. Mean $+/-\mathrm{CV}$. IS = initial solution, $\mathrm{S}=$ Supernatant, $\mathrm{E}=$ nanoparticle eluate, $\mathrm{C} 100 \%$ = calculated $\mathrm{GH}$ concentration based on $100 \%$ yield. C) And D) Linearity of the immunoassay ( 9 calibrator values, range $0.750-0.05 \mathrm{ng} / \mathrm{mL}$ ) with and without nanoparticle preprocessing, respectively. Nanoparticle preprocessing maintains the linearity of the immunoassay $\left(R^{2}=0.986,0.982\right.$, with and without the nanoparticles, respectively).

\section{Concentration factor calculation}

Enhanced detection sensitivity is achieved because the nanoparticles effectively harvest virtually $100 \%$ of the $\mathrm{HGH}$ from the full $30 \mathrm{~mL}$ urine volume, and concentrate the urinary HGH down to a volume of $300 \mu \mathrm{L}$. The increase in effective concentration of HGH is:

\section{(vs/ve) $\cdot \mathrm{C}=\mathrm{Ci}$}

Where vs. $=$ original sample volume, ve $=$ volume of nanoparticle eluate, $\mathrm{C}=$ initial concentration of analyte in the sample, and $\mathrm{Ci}=\mathrm{final}$ increased expected concentration. Consequently a 100 times higher concentration of HGH is introduced into the Immulite assay, compared to the unconcentrated urine. The nanoparticles are buoyant open mesh ( $>95 \%$ solute) hydrogel spheres (Figure $3 \mathrm{~A}$ ) containing a core with an immobilized high affinity chemical bait. When mixed with the urine, the nanoparticles remain in colloid suspension to achieve extremely rapid access $[10,11]$ and sequestration of the HGH target analyte. The bait binds HGH with high affinity $\left(\mathrm{K}_{\mathrm{D}}<10^{-12} \mathrm{M}\right.$, Figure 1$)$, such that no detectable $\mathrm{HGH}$ can be measured outside the nanoparticles in the fluid phase.

\section{Concentration method verification}

The nanoparticle concentration method was verified with standard samples that were run by trained personnel in a blind fashion, $\mathrm{N}=21$. The acceptance criteria were percentage difference (Diff \%) $<10 \%$, as defined by the following equation:

$$
\text { Diff } \%=(\text { Meas }- \text { True }) / \text { True }{ }^{\star} 100
$$

Where true is the true HGH concentration in the blind standard sample and Meas is the HGH concentration value obtained by nanoparticle Immulite assay performed in a blind fashion.

$100 \%$ of the samples passed the $10 \%$ criteria (Table 1 ).

\section{Full process precision}

The full-process within-run $\mathrm{CV}$ for the nanoparticle based measurement of urinary $\mathrm{HGH}$ was $9.0 \%(\mathrm{~N}=10)$, with virtually $100 \%$ HGH capture efficiency and $100 \%$ elution yield (Figure 3B, Initial Solution Average $(\mathrm{CV}) \mathrm{ng} / \mathrm{mL}=0.128(4.0 \% \mathrm{CV}) \mathrm{ng} / \mathrm{mL}$; Supernatant $<0.05 \mathrm{ng} / \mathrm{mL}$; Eluate Actual Measurement, Average $(\mathrm{CV})=2.095$ $(9.0 \% \mathrm{CV}) \mathrm{ng} / \mathrm{mL}$; Calculated $100 \%$ yield $2.048 \mathrm{ng} / \mathrm{mL})$. The between run precision $(\% \mathrm{CV})$ without the particles was $9.5 \%$ and the between run precision $(\% \mathrm{CV})$ with the nanoparticles was $8.1 \%$. The $\mathrm{HGH}$ concentration in the supernatant following nanoparticle incubation was always below the limit of detection for the Immulite. The between run analysis was done over 2 working weeks. (Initial Solution Average $(\mathrm{CV}) \mathrm{ng} / \mathrm{mL}=0.106(9.5 \% \mathrm{CV}) \mathrm{ng} / \mathrm{mL}$; Supernatant $<0.05 \mathrm{ng} / \mathrm{mL}$;

\begin{tabular}{|c|c|c|}
\hline True [Ng/MI] & Measured [Ng/MI] & Diff \% \\
\hline 2.95 & 2.91 & 1.37 \\
\hline 3.61 & 3.6 & 0.28 \\
\hline 1.22 & 1.2 & 1.67 \\
\hline 0.454 & 0.437 & 3.89 \\
\hline 0.15 & 0.154 & -2.60 \\
\hline 0.38 & 0.385 & -1.30 \\
\hline 1.63 & 1.51 & 7.95 \\
\hline 4.35 & 4.52 & -3.76 \\
\hline 6.89 & 6.76 & 1.92 \\
\hline 0.348 & 0.34 & 2.35 \\
\hline 0.354 & 0.389 & -9.00 \\
\hline 10.000 & 10.6 & -5.66 \\
\hline 0.360 & 0.336 & 7.14 \\
\hline 2.200 & 2.14 & 2.80 \\
\hline 0.083 & 0.085 & -2.35 \\
\hline 7.610 & 7.58 & 0.40 \\
\hline 2.130 & 2.140 & -0.47 \\
\hline 1.470 & 1.390 & 5.76 \\
\hline 2.440 & 2.430 & 0.41 \\
\hline 0.891 & 0.879 & 1.37 \\
\hline 0.778 & 0.757 & 2.77 \\
\hline
\end{tabular}

Table 1:Nanoparticle pre-processing step passed the concentration method verification test in our laboratory, $\mathrm{N}=21$. TRUE = true value of $\mathrm{HGH}$ concentration in the standard sample, MEASURED $=\mathrm{HGH}$ concentration measured in the standard sample in a blind fashion, DIFF\% $=($ MEASURED - TRUE $) / T R U E * 100$. Acceptability criteria $=$ DIFF $\%<10 \%$. 


\begin{tabular}{|c|c|c|c|}
\hline & Urine $\mathbf{h G H}$ concentration, $\mathbf{p g} / \mathbf{m L}$ & Urine $\mathbf{h G H}$ concentration, $\mathbf{n g} / \mathbf{g} \mathbf{~ c r e a t i n i n e}$ & $\mathbf{S e r u m} \mathbf{h G H}$ concentration, $\mathbf{n g} / \mathbf{m L}$ \\
\hline 2.5 percentile $(0.90$ confidence interval) & $0.64(0.52-0.84)$ & $0.05(0.04-0.06)$ & $0.13(0.11-0.19)$ \\
\hline 97.5 percentile $(0.90$ confidence interval) & $16.85(9.92-28.369)$ & $5.82(2.34-9.7)$ & 0.39 \\
\hline Median & 2.75 & 0.98 \\
\hline Average & 5.01 & 0.41 & 2.42 \\
\hline
\end{tabular}

Table 2: Reference Values of spot urine HGH measured with nanoparticle-Immulite assay and serum HGH measured with Immulite Growth Hormone test.

Eluate Actual Measurement, Average $(\mathrm{CV})=0.576(8.1 \% \mathrm{CV}) \mathrm{ng} / \mathrm{mL}$; Average total yield $(\mathrm{CV})=91 \%(13.2 \% \mathrm{CV})$.

\section{Full process linearity}

Linearity of the immunoassay ( 9 calibrator values, range 0.750-0.05 $\mathrm{ng} / \mathrm{mL}$ ) was equivalent with and without nanoparticle pre-processing (Figure 3C and 3D, Slope (standard deviation) $=0.74(0.03), 0.79(0.04)$; Intercept (standard deviation) $=-0.02(0.02),-0.02(0.02) ; \mathrm{R}^{2}=0.986$, 0.982 ; Residual standard deviation $=0.0286,0.0347$ with and without the nanoparticle processing, respectively).

\section{Reference values for HGH in spot urine}

In our cohort of volunteers, the $95 \%$ reference values for hGH in spot urine normalized to specific gravity were $0.64-16.85 \mathrm{pg} / \mathrm{mL}(0.05$ $-5.82 \mathrm{ng} / \mathrm{g}$ creatinine) (Table 2). Reference values and confidence intervals were calculated with the bootstrap method [14] in R Statistical Software [15]. These data reveal that there is a one thousand fold difference in the concentration of physiologic HGH in spot urine compared to the value in serum for the same patient, measured at the same point in time (Table 2).

\section{Inter-laboratory proficiency assessment}

To verify that this methodology could be validated across multiple laboratories, we did a side by side comparison of nanoparticle preprocessed urine in two different international laboratories using two different immunoassays. The Immulite immunoassay as described above was conducted in George Mason University, USA and a recently developed research grade immunoassay validated for serum samples [16] was performed in IMIM Hospital del Mar, Spain. Four urine proficiency samples spiked with recombinant hGH were prepared and incubated with $1 \mathrm{~mL}$ of poly(NIPAm/RBB) nanoparticles. The nanoparticle-processed eluate was measured by the USA and Spain laboratories independently. The correlation, spanning the range of $0.003-0.3 \mathrm{ng} / \mathrm{mL}$ calculated urine concentration $(0.08-11 \mathrm{ng} / \mathrm{mL}$ measured hGH urine concentration), was $\mathrm{y}=0.8454 \mathrm{x}+0.2386, \mathrm{R}^{2}=$ 0.9967 , where $\mathrm{x}=$ USA results and $\mathrm{y}=$ Spain results.

Thus, nanoparticle preprocessing constitutes a reliable means of establishing a normal baseline value for $\mathrm{HGH}$ in urine. The important question can now be addressed as to whether the excretion of HGH in the urine has longer time course than the spike of $\mathrm{HGH}$ in serum following exogenous administration. Moreover, it will now be possible to study factors that affect urinary HGH excretion and isoform proportions. This is important because urinary HGH measurement may permit the detection of HGH doping that would otherwise be missed with serum testing [6].

Bait functionalized hydrogel nanoparticles [10,11] are a cost effective, user friendly technology that, in this study, permitted the reliable measurement of a low abundance protein analyte $(\mathrm{HGH})$ in urine with a clinical grade immunoassay that until now is used for serum/plasma based analysis. Once the correct bait chemistry is matched to optimal analyte capture, this nanoparticle technology can be applied to the measurement of any analyte in any body fluid using any appropriate measurement platform ranging from immunoassays to mass spectroscopy-based multiple reaction monitoring [10].

\section{Acknowledgments}

This work was supported partially by 1) George Mason University, 2) US Anti-Doping Agency, 3) the Italian Istituto Superiore di Sanita' in the framework of the Italy/USA cooperation agreement between the U.S. Department of Health and Human Services, George Mason University, and the Italian Ministry of Public Health, and 4) Grant 1R21AR061075 - 01 to LAL from NIAMS/NIH. The authors are grateful for fruitful scientific discussions with Simona Pichini, Francesco Facchiano, Ricardo Gutiérrez Gallego, and Jordi Segura.

\section{References}

1. High WM Jr, Briones-Galang M, Clark JA, Gilkison C, Mossberg KA, et al. (2010) Effect of growth hormone replacement therapy on cognition after traumatic brain injury. J Neurotrauma 27: 1565-1575.

2. Ross JL, Quigley CA, Cao D, Feuillan P, Kowal K, et al. (2011) Growth hormone plus childhood low-dose estrogen in Turner's syndrome. N Engl J Med 364 1230-1242.

3. Giannoulis MG, Martin FC, Nair KS, Umpleby AM, Sonksen P (2012) Hormone Replacement Therapy and Physical Function in Healthy Older Men. Time to Talk Hormones? Endocr Rev 33: 314-377.

4. Holt RI, Sönksen PH (2008) Growth hormone, IGF-I and insulin and their abuse in sport. Br J Pharmacol 154: 542-556.

5. Holt RI (2011) Detecting growth hormone abuse in athletes. Anal Bioanal Chem 401: 449-462.

6. Sönksen PH, Holt RI (2009) GH \& IGF Research issue on doping with growth hormone. Growth Horm IGF Res19: 283-284.

7. Quade A, Rahn M, Schweikert HU, Bidlingmaier F, Klingmüller D (1993 Urinary excretion of $\mathrm{GH}$ in healthy individuals and patients with acromegaly, hypopituitarism and dwarfism. Acta Endocrinol (Copenh) 128: 24-28.

8. Hauffa BP, Lehmann N, Bettendorf M, Mehls O, Dörr HG, et al. (2004) Centra reassessment of $\mathrm{GH}$ concentrations measured at local treatment centers in children with impaired growth: consequences for patient management. Eur J Endocrinol 150: 291-297.

9. Baumann G, Abramson EC (1983) Urinary growth hormone in man: evidence for multiple molecular forms. J Clin Endocrinol Metab 56: 305-311.

10. Tamburro D, Fredolini C, Espina V, Douglas TA, Ranganathan A, et al. (2011) Multifunctional Core-Shell Nanoparticles: Discovery of Previously Invisible Biomarkers. J Am Chem Soc 133: 19178-19188.

11. Luchini A, Geho DH, Bishop B, Tran D, Xia C, et al. (2008) Smart hydroge particles: biomarker harvesting: one-step affinity purification, size exclusion, and protection against degradation. Nano Lett 8: 350-361.

12. Fredolini C, Tamburro D, Gambara G, Lepene BS, Espina V, et al. (2009) Nanoparticle technology: amplifying the effective sensitivity of biomarker detection to create a urine test for hGH. Drug Test Anal 1: 447-454.

13. Fredolini C, Meani F, Reeder KA, Rucker S, Patanarut A, et al. (2008) Concentration and Preservation of Very Low Abundance Biomarkers in Urine, such as Human Growth Hormone $(\mathrm{hGH})$, by Cibacron Blue F3G-A Loaded Hydrogel Particles. Nano Res 1: 502-518.

14. Solberg HE (2001) Establishment and Use of Reference Values: In Burtis CA, Ashwood ER, Bruns DE, Tietz NW (Eds) Tietz Fundamentals of Clinical Chemistry. WB Saunders, Philadelphia, 251-261.

15. R computational team (2012) R: A language and environment for statistical computing; R foundation for statistical computing: Vienna, Austria.

16. Bidlingmaier M, Suhr J, Ernst A, Wu Z, Keller A, et al. (2009) High-sensitivity chemiluminescence immunoassays for detection of growth hormone doping in sports. Clin Chem 55: 445-453. 